\title{
Solar panels optimization for a better efficiency and for hot water production: Determination of the exchange coefficient.
}

\author{
Biram DIENG ${ }^{1}$; Jean Pierre TINE ${ }^{1}$; Senghane MBODJI ${ }^{1}$; \\ Ibrahima FALL ${ }^{1}$ and Sokhna Maty Sarr DEME ${ }^{2}$ \\ ${ }^{1}$ Research team in renewable energies, materials and laser of Department of Physics, \\ Alioune Diop University of Bambey, Bambey, Senegal \\ ${ }^{2}$ CEDT "Le G15" Dakar, Senegal \\ E-mail: biram.dieng@uadb.edu.sn
}

\begin{abstract}
Photovoltaic panels' efficiency strongly depends on temperatures. In hot weather, the yield of the PV panels is low due to the fact that the absorbed solar radiation which is not converted into electricity rises the PV cells' temperature, causing the decline of the electrical efficiency.

In the proposed method, we developed a support comprising a heat exchanger on which the photovoltaic panel will be installed. This is an application of a relatively new technology. The resulting component photovoltaic/heat exchanger not only will produce electricity, but will also serve as heat source because the amount of solar energy absorbed and converted into heat can be recovered and used for heating or for domestic uses.

In this study, a hybrid prototype is developed and experimental measurements carried out to evaluate the electrical and thermal performance. Thus, a significant improvement of the electrical yield is realized and hot water is produced that can be used for domestic uses. Then, a comparison is done between the hybrid prototype and a simple PV panel with the same characteristics, which is installed on a simple support. We also determine the behavior of the panel's exchange coefficient as a function of the water outlet temperature. The results of this experiment show that the hybrid prototype can be a good alternative to simple photovoltaic modules.
\end{abstract}

Keywords: hybrid panel, heat exchanger, thermal performance and efficiency.

\section{Introduction}

Preliminary studies have shown that $1^{\circ} \mathrm{C}$ increase in temperature compared to its standard value $\left(25^{\circ} \mathrm{C}\right)$ causes a $0.5 \%$ decrease of the efficiency. Thus, to improve the performance of the PV panels, we propose in this document a method to reduce the temperature.

The conceived system comprises a photovoltaic panel and a coil heat exchanger which is connected to the rear of the PV panel and serves as a support. The coil heat exchanger utilizes water as coolant and constitutes a cooling system which recuperates the heat from the panel (heated by the radiation not converted into electricity) and from the surrounding air that also heats the panel by convection. A major part of the heat recovered is transferred to the coolant (water) circulating inside the coil heat exchanger made of copper. From the system built, an energy assessment is carried out based on parameter measurements. Then, a comparison is made between the conceived system and a simple PV panel of the same characteristics.

\section{Experimental apparatus}

The objective of the experiment is to study the effect of the cooling on the following parameters of the photovoltaic panel: the output power, the electrical efficiency and the thermal efficiency. To do so, we compare the performance of two identical photovoltaic panels, one combined to a coil heat exchanger fixed to its rear, the other one installed alone. 


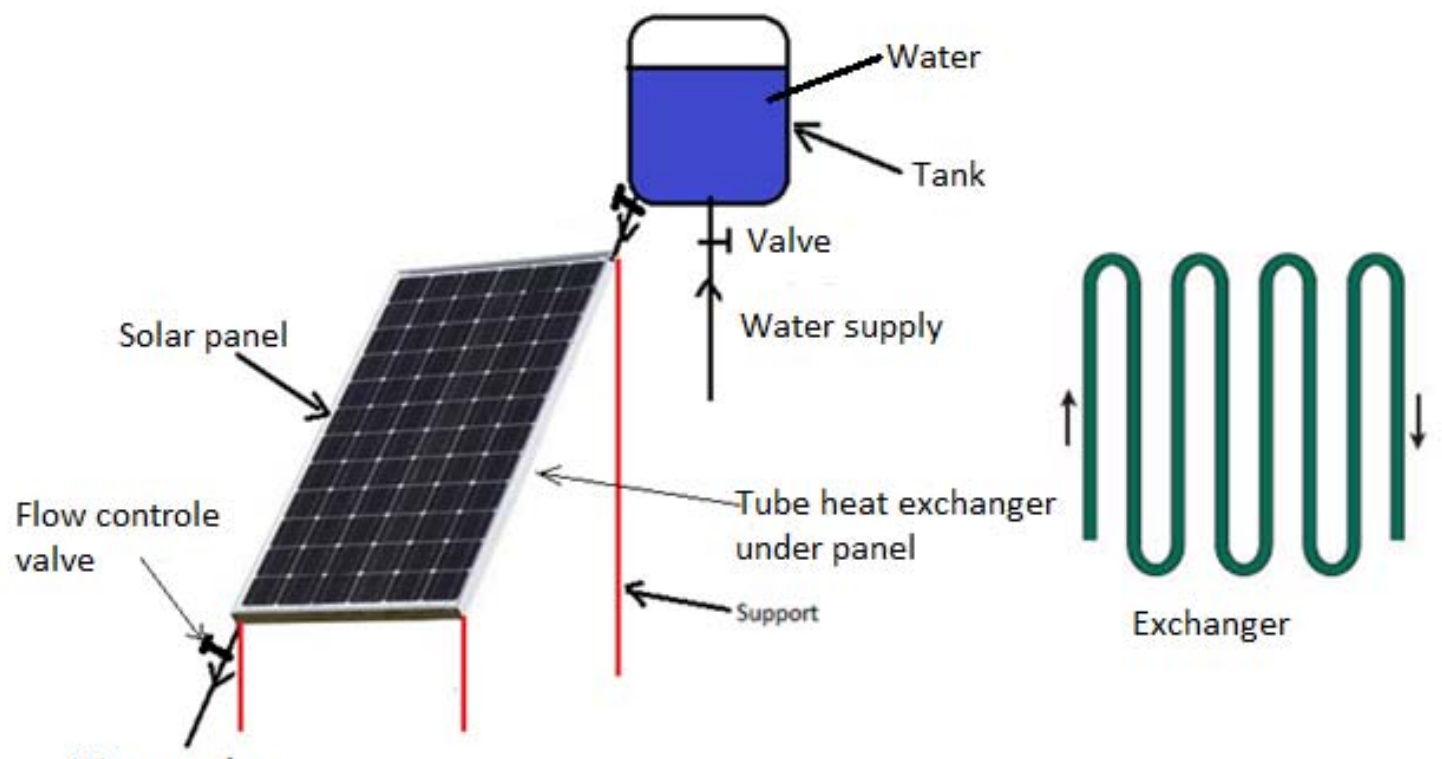

Water outlet

Figure 1: Photovoltaic solar panel installed on a support consisting of a coil heat exchanger

The device comprises a photovoltaic solar panel placed on a support with a coil heat exchanger made of copper, a cold water tank and flow control valves.

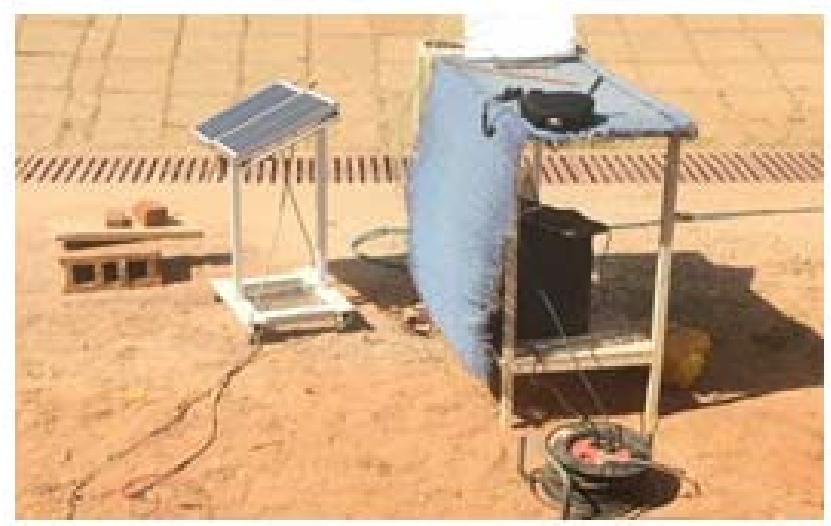

Figure 2: View of experimental apparatus with the hybrid prototype and the solar panel installed alone

\begin{tabular}{|l|l|}
\hline Nominal power Wc & 50 \\
\hline Voltage Wmp & 18 \\
\hline Current Imp & 2,85 \\
\hline Vco & 22,2 \\
\hline Icc & 3,09 \\
\hline$\beta$ & $-0,48 \% /{ }^{\circ} \mathrm{C}$ \\
\hline dimensions & $540 \times 670 \times 35$ \\
\hline Operating temperature & $-40 \mathrm{à}+85^{\circ} \mathrm{C}$ \\
\hline Yield & $21,3 \%$ \\
\hline
\end{tabular}

Figure 3: Characteristics of the two identical solar panels used in the experiment

The electrical experimental apparatus is composed of ammeters, voltmeters, rheostats, electrical conductors, thermocouples, a data recorder and a solarimeter. 


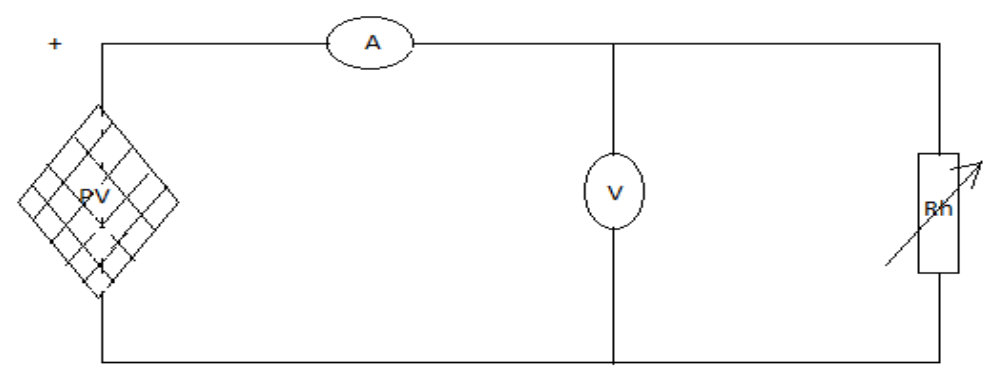

Figure 4: Scheme of the electrical experimental apparatus

The solar panel is associated to a support consisting of a coil heat exchanger made from a copper crown of $1 / 4$ inch diameter.

The coil heat exchanger in contact with the rear of the photovoltaic panel recover the heat from the solar panel through the water circulating in it by gravitation and contained in the tank (figure 1). At the outlet of the exchanger, a tap with a flow control is connected, though which the hot water produced is collected. To optimize the heat transfer, the coil heat exchanger is covered with a polystyrene insulation.

\section{Results and discussion}

In this part, the experimental results obtained from the two photovoltaic panels (hybrid and simple) are discussed. A comparison of the behavior of the electrical parameters of the two devices is carried out. For that, the two panels are placed under sunlight between $11 \mathrm{a} . \mathrm{m}$. and $3 \mathrm{p} . \mathrm{m}$. with an inclination angle of $14^{\circ}$ north, corresponding to the latitude of the place. Thermocouples are connected to different places (Top and bottom of the panels, inlet and outlet of the heat exchanger) for temperature measurements. In addition a solarimeter is installed to measure the illuminance.

The results show that for the simple solar panel, the temperature above and below the panel increases as function of the illuminance. The temperature is slightly higher below the panel than above it. This is due to the fact that the top is more exposed to natural convection. However, for the hybrid panel, the cooling causes a decrease of both temperatures which tend to equalize after 2 hours of operation i.e. around 2 p.m. In addition, a significant difference (that gradually increases) is noticed between the inlet and outlet temperature of the cooling water. The reason is the heat dissipated by the panel is recovered by the water circulating inside the heat exchanger.

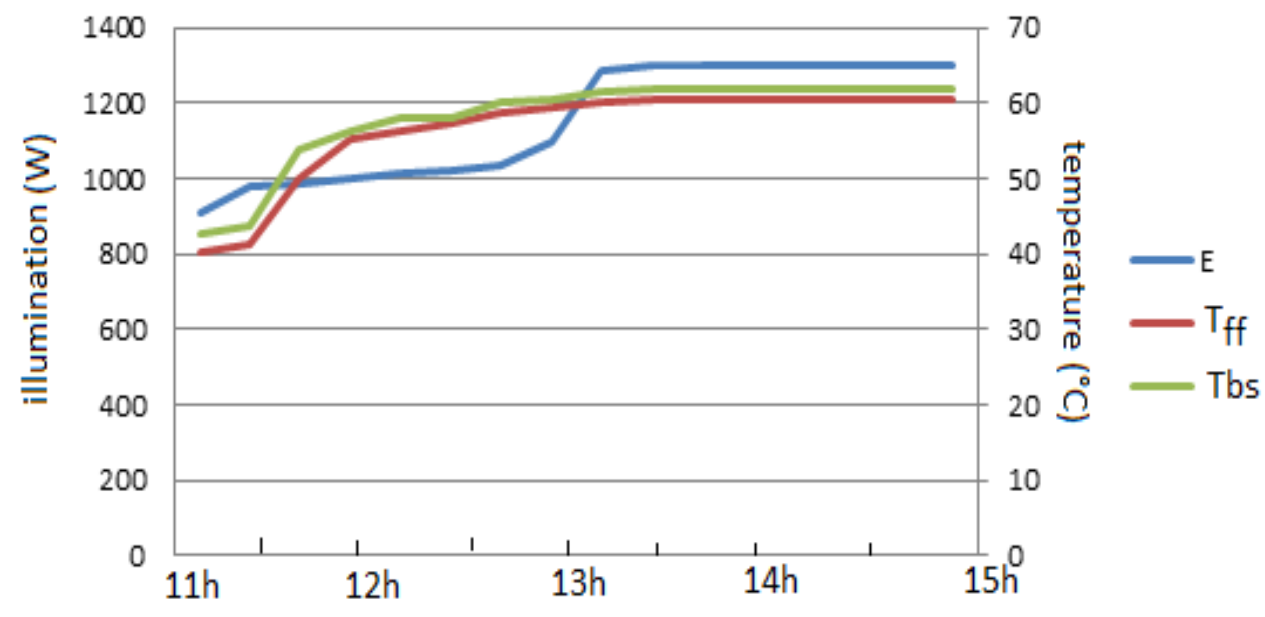

Figure 5: Evolution of the different temperatures on the simple panel

Tff: Temperature above the panel

Tbs: Temperature below the panel

E: Illuminance 


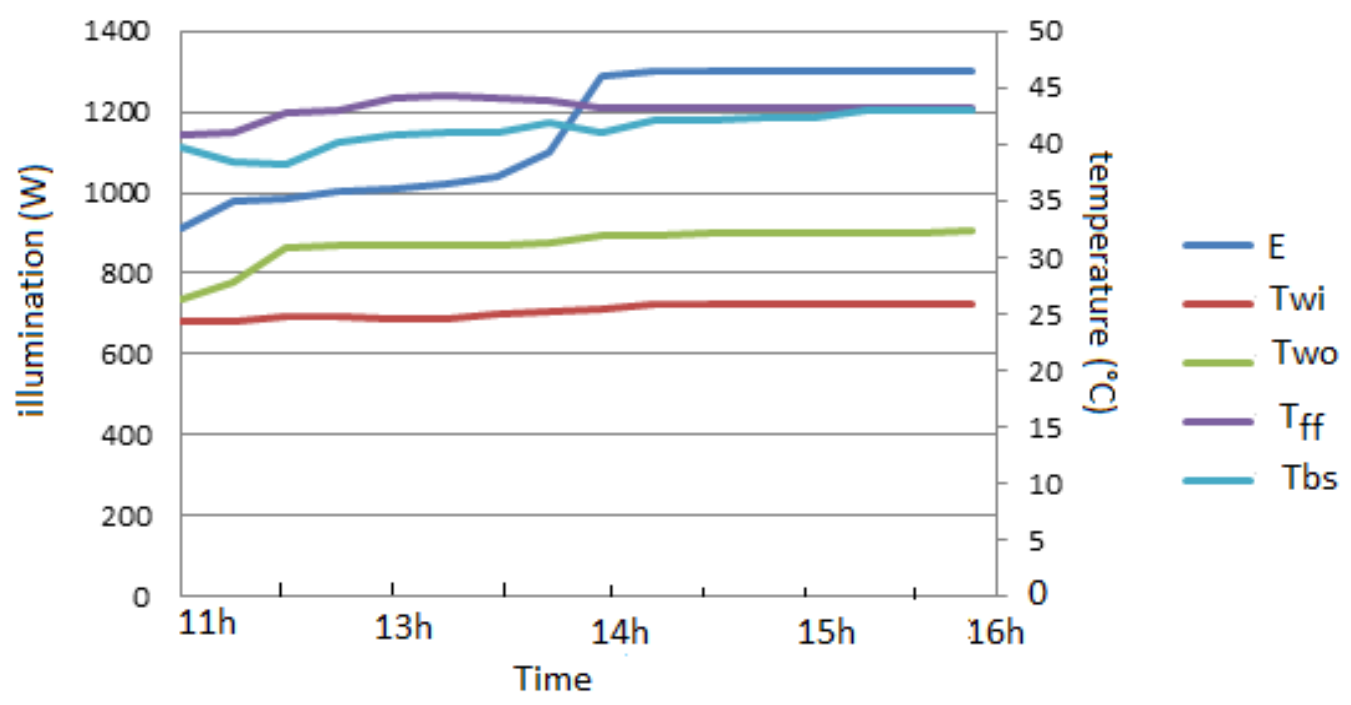

Figure 6: Evolution of the different temperatures on the hybrid panel

Twi: Inlet temperature of the water

Two: Outlet temperature of the water

For the hybrid panel, the maximum temperature measured is $43^{\circ} \mathrm{C}$ against $62^{\circ} \mathrm{C}$ for the simple one. Indeed, the heat exchanger associated to the panel causes the decrease of the temperature of the underside of the panel to a certain value. The water used for the cooling, which gets in the coil heat exchanger at $25^{\circ} \mathrm{C}$, comes out at $32^{\circ} \mathrm{C}$. The water is then heated enough to be used in sanitary.

\section{III.1. Electrical performance of the collectors}

\section{- $\quad$ Current - voltage characteristic}

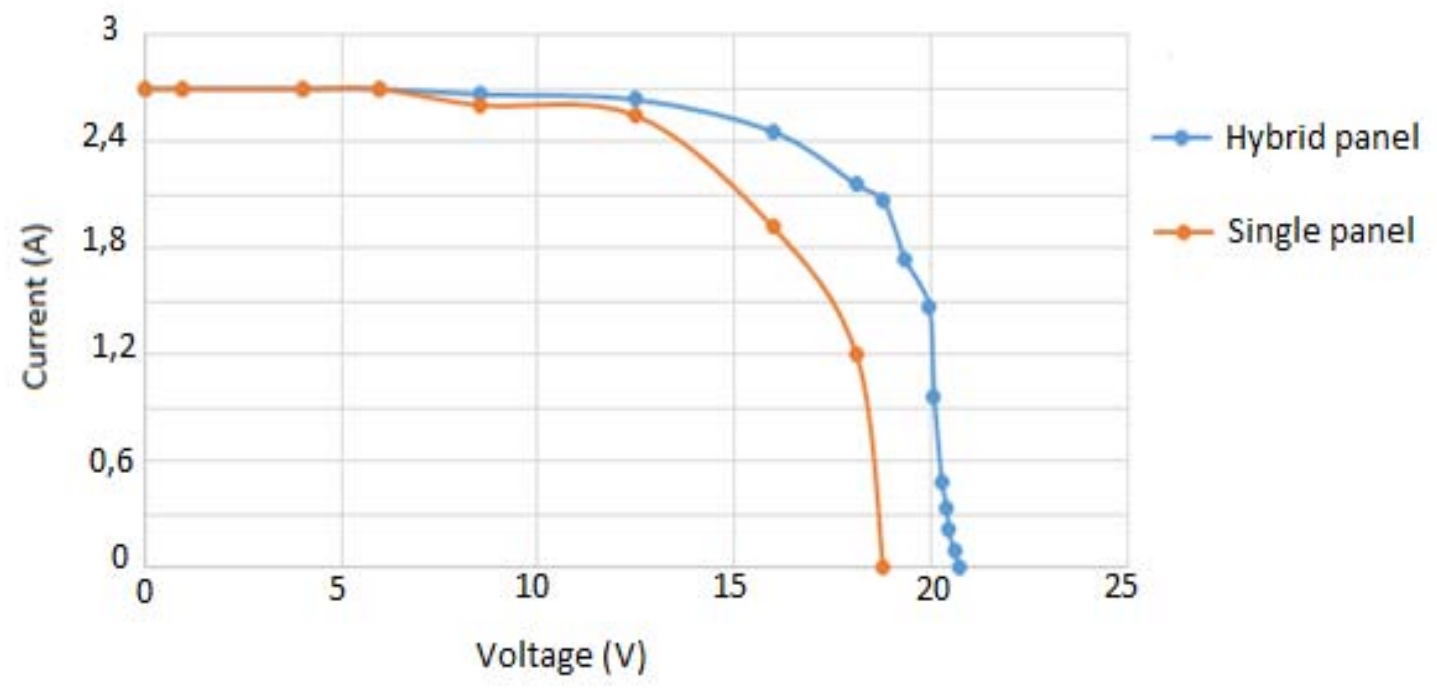

Figure 7: Current - voltage characteristics of the two panels

The current-voltage characteristic show that the short-circuit current has the same value for both panels and is equal to $2.7 \mathrm{~A}$. On the other hand, the open circuit voltage is respectively $20.73 \mathrm{~V}$ for the hybrid panel and 18.78 $\mathrm{V}$ for the simple panel.

\section{- Electric power}

The electric power is calculated by the formula below:

$$
P=U * I
$$

The power-voltage characteristic is estimated by assuming a constant illuminance value equal to $1000 \mathrm{~W} / \mathrm{m}^{2}$ for the two panels. 


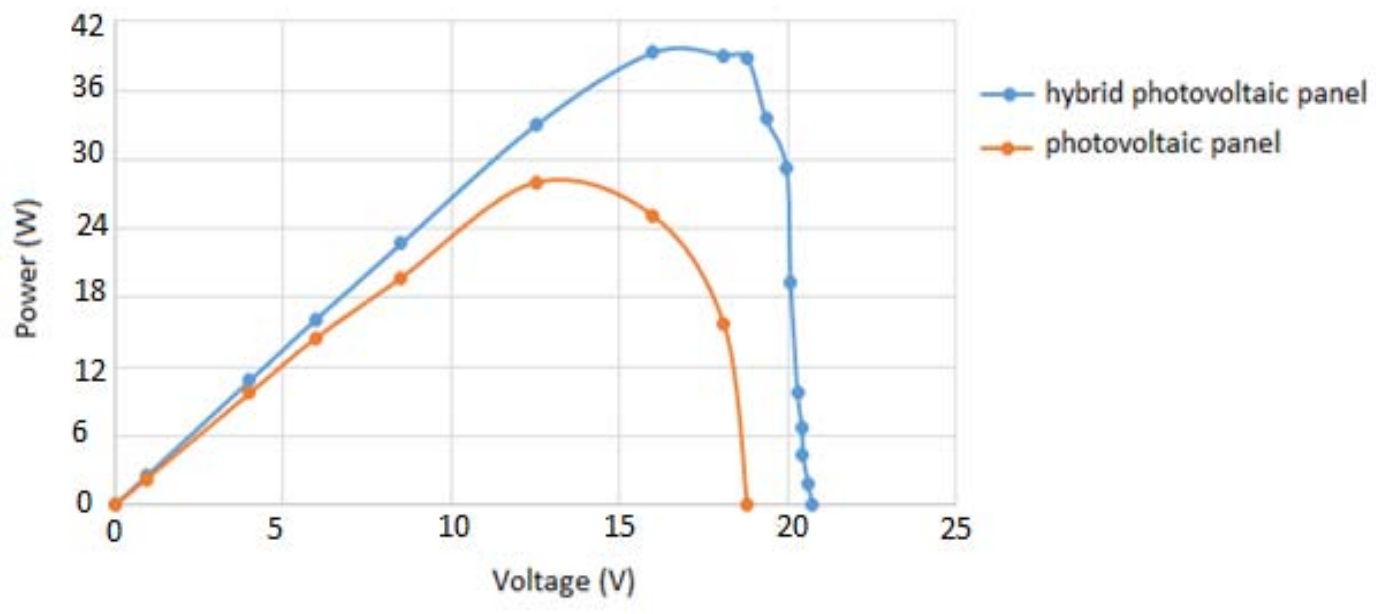

Figure 8: Power - voltage characteristics of the two panels

It is noticed that due to the cooling effect, the electric power of the hybrid panel is greater than that of the simple panel. In addition, the maximum power point is improved by cooling.

For a constant illuminance value of $1000 \mathrm{~W} / \mathrm{m}^{2}$, the maximum power measured is respectively $41.25 \mathrm{~W}$ for the hybrid panel and $28.25 \mathrm{~W}$ for the simple one. This results shows the high dependency of the electric power on the operating temperature. The cooling enable an optimization of the electrical parameters of the photovoltaic module.

\section{- Electrical efficiency of the solar panel}

It's the ratio between the electric power delivered by the photovoltaic solar module and the power of the illuminance received on the surface of the panel. It's given by:

$$
\eta=\frac{U * I}{E * S}
$$

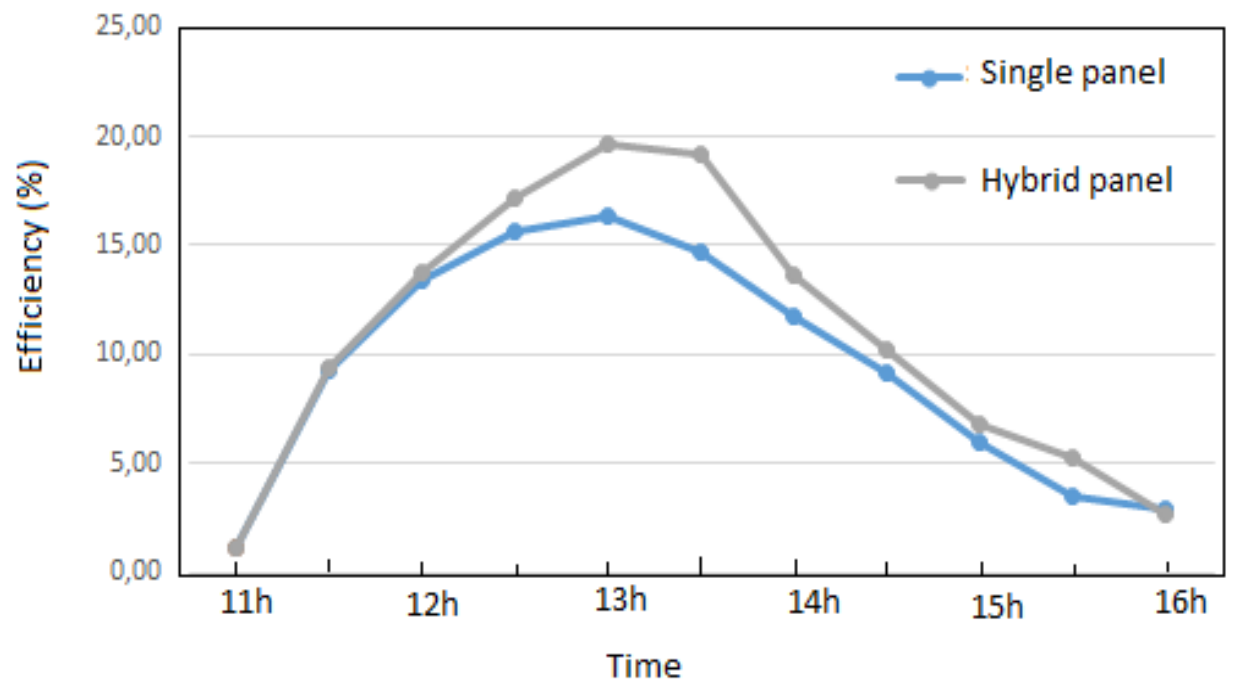

Figure 9: Electrical efficiency of the two panels

The electrical efficiency is greater for the hybrid panel especially when the cooling is more effective. The maximum value obtained is $19.8 \%$ for the hybrid panel and $16 \%$ for the simple panel. These maximum values are recorded when the cooling and the illuminance are optimum.

\section{- Thermal efficiency}

The thermal efficiency is determined by the ratio between the thermal power absorbed by the water and the power of the incident illuminance.

$$
\eta_{t h}=\frac{\rho Q_{v} c \Delta T}{E S}
$$




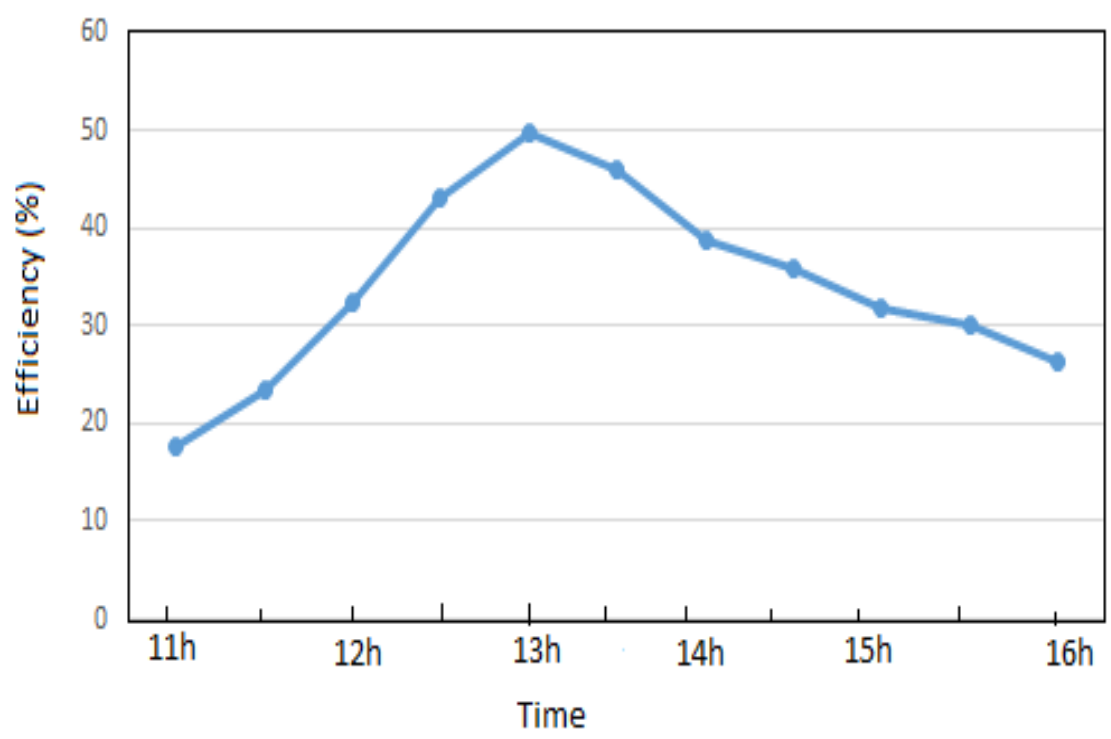

Figure 10: Thermal efficiency of the hybrid panel

The thermal efficiency is greater than the mechanical efficiency. Its maximum value (49.8\%) is obtained at 1 p.m. when the illuminance is at its maximum.

The efficiency is related to some parameters such as the difference between the inlet and the outlet temperature of the water, the convective exchange coefficient between the water and the tubes and the conductive exchange coefficient of the panel.

\section{Determination of the heat exchange coefficient of the panel}

The hybrid panel is insulated by its back side which allows us to assume that all the amount of heat released by the panel is completely absorbed by the water circulating in the heat exchanger. This equality of the two flows will allow us to determine the exchange coefficients.

He heat flux calculated from the water fluid is:

$$
\emptyset=\dot{m} c \Delta T=\rho Q_{v} c \Delta T
$$

With $\dot{m}$ being the mass flow of water, $\mathrm{c}$ the specific heat and $\Delta \mathrm{T}$ the temperature difference between the inlet and the outlet of the water; $\rho$ is the voluminal mass and $Q v$ is the volume flow rate.

That same flow can be obtained from the panel:

$$
\emptyset=K S \Delta T^{\prime}
$$

With $\mathrm{K}$ the exchange coefficient, $\mathrm{S}$ : exchange surface and $\Delta \mathrm{T}^{\prime}$ is the temperature difference between the two faces of the panel.

From these two equal equations, we deduce the overall coefficient of the panel. 


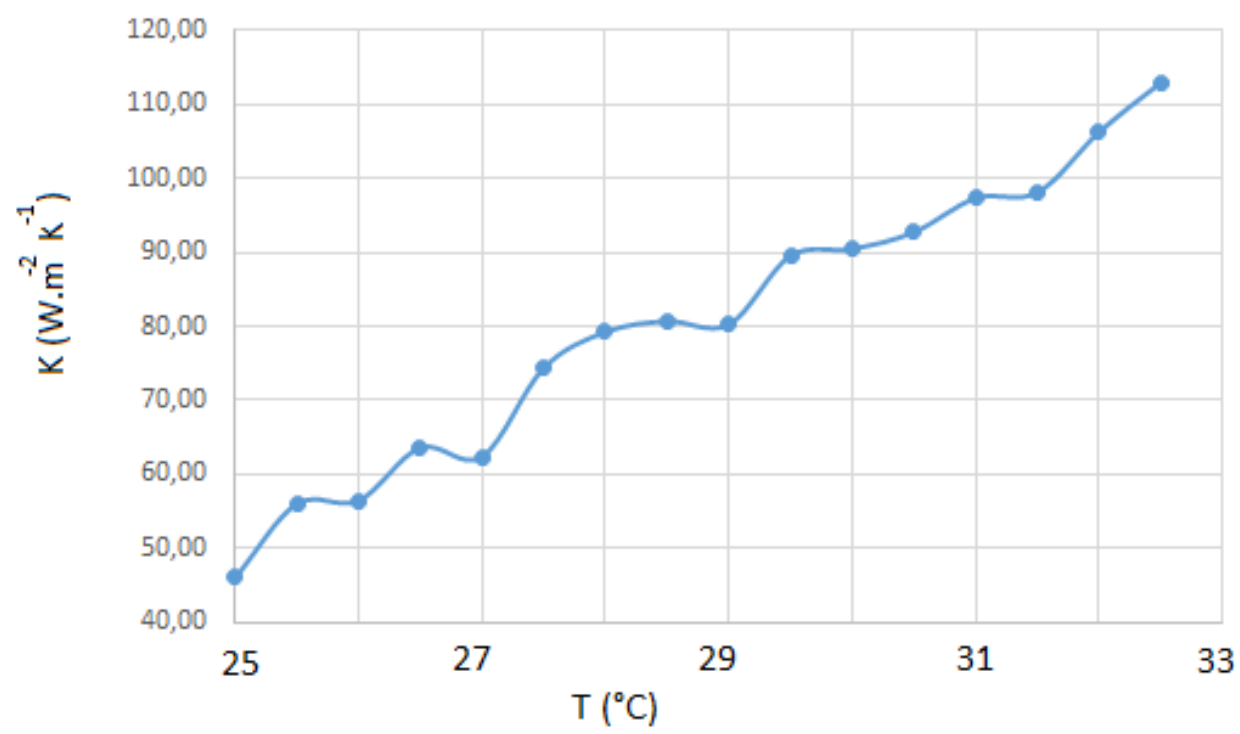

Figure 11: Exchange coefficient as a function of the water outlet temperature (water inlet temperature $25^{\circ} \mathrm{C}$ )

We note that the evolution of the heat exchange coefficient is linear as a function of the temperature of the water leaving the exchange, which is in agreement with the literature. Unlike the panel with simple support whose exchange coefficient increases with the temperature of the rear face of the panel which is the source of the storage in the panel.

\section{Conclusion}

An experimental study of two devices, a simple photovoltaic panel and another of the same characteristics but combined to a coil heat exchanger is carried out. The hybrid panel has proved to be more efficient in converting the solar energy.

The obtained results show also that the performance of photovoltaic panels depend on the ambient temperature. In addition, the solar energy that heats the panel is recovered and used for other applications. The heat exchange coefficient changes linearly as a function of the water outlet temperature from the exchanger.

\section{Bibliography}

[1] Skoplaki E., Palyvos J.A., (2009) "On the temperature dependence of photovoltaic module electrical performance: A review of efficiency/power correlations", Solar Energy, Volume 83, Issue 5, Pages 614-624.

[2] Stein, J.S., (2011). "Coupled Performance and Reliability Modeling of PV Systems and Components: Evaluating Design and O\&M Strategies", Dallas", Texas.

[3] Notton, G., Lazarov, V., Stoyanov, L., (2010). "Optimal sizing of a grid connected PV system for various PV module technologies and inclinations, inverter efficiency characteristics and location”. Renewable Energy 35, 541-554.

[4] Ren, H., Gao, W., Ruan, Y., 2009. "Economic optimization and sensitivity analysis of photovoltaic system in residential buildings". Renewable Energy 34, 883-889.

[5] P. Singh, S.N.Singh, M. Lal, M.Husain, Solar Energy Materials \& Solar Cells 92 (2008) 1611-1616

[6] Anas Al Tarabsheh, SpyrosVoutetakisb, Athanasios I. Papadopoulosb, Panos Seferlisb,c, Issa Etiera, Omar Saraereh, Investigation of Temperature Effects in Efficiency Improvement of NonUniformly Cooled Photovoltaic Cells, Chemical Engineering Transactions (2013) Vol. 35.

[7] A. Muzaffar, Hafiz.M. Ali, W. Moazzam, and M. Babar Saeed, Performance enhancement of PV cells through micro-channel cooling, AIMS Energy (2015) 3(4), pp. 699-710.

[8] S. Nizetic, D. C`oko, A. Yadav, F. Grubišic'-C``abo, Water spray cooling technique applied on a photovoltaic panel: The performance response, Energy Conversion and Management (2016)108, pp. 287-296. 